\title{
Assessment of blood-products use as predictor of pulmonary complications and surgical-site infection after hepatectomy for hepatocellular carcinoma
}

\author{
Hiroaki Shiba $\cdot$ Yuji Ishii $\cdot$ Yuichi Ishida $\cdot$ Shigeki Wakiyama \\ Taro Sakamoto · Ryusuke Ito · Takeshi Gocho · Tadashi Uwagawa • \\ Shoichi Hirohara $\cdot$ Yoshiaki Kita $\cdot$ Takeyuki Misawa $\cdot$ Katsuhiko Yanaga
}

Received: 4 December 2007/ Accepted: 28 January 2008/Published online: 16 December 2008

(C) Springer 2008

\begin{abstract}
Background In perioperative management after hepatectomy, some patients require fresh frozen plasma (FFP) to treat coagulopathy associated with blood loss. However, several studies have suggested a correlation between blood products and pulmonary complications or surgical-site infection (SSI).

Methods The subjects were 99 patients who underwent hepatectomy for hepatocellular carcinoma without plasma exchange for postoperative liver failure in the Department of Surgery, Jikei University Hospital, between January 2000 and December 2006. We investigated the association of 16 factors including age; gender; preoperative $\mathrm{ICG}_{\mathrm{R} 15}$; type of resection; concomitant resection of other digestive organs; duration of operation; blood loss; hepatitis virus status; postoperative minimum platelet count, maximum serum total bilirubin (max T-Bil), minimum serum albumin, or minimum prothrombin time; and the dose of redblood-cell concentration (RC), FFP, platelet concentration, or albumin given in relation to postoperative pulmonary complications and SSI.

Results In univariate analysis, pulmonary complications were correlated with gender $(P=0.012)$, max T-Bil $(P=0.043)$, dose of RC given $(P=0.007)$, dose of FFP given $(P<0.001)$, and dose of albumin given $(P<0.001)$. In multivariate analysis, pulmonary complications were correlated with FFP given $(P=0.031)$ and albumin given
\end{abstract}

H. Shiba $(\bowtie) \cdot$ Y. Ishii $\cdot$ Y. Ishida $\cdot$ S. Wakiyama.

T. Sakamoto - R. Ito - T. Gocho - T. Uwagawa - S. Hirohara

Y. Kita $\cdot$ T. Misawa $\cdot$ K. Yanaga

Department of Surgery, Jikei University School of Medicine,

3-25-8, Nishi-Shinbashi, Minato, Tokyo 105-8461, Japan

e-mail: hs0817@jikei.ac.jp
$(P=0.020)$, while the incidence of SSI was not correlated with any factors.

Conclusion Excessive FFP and albumin administration may cause pulmonary complications after hepatectomy.

Keywords Fresh frozen plasma - Hepatectomy · Hepatocellular carcinoma P Pulmonary complication . Surgical-site infection

\section{Introduction}

In Japan, blood products such as fresh frozen plasma (FFP) and albumin have been administered rather liberally after hepatectomy for hepatocellular carcinoma (HCC) to maintain plasma osmotic pressure and coagulation factor levels [1,2] because appropriate guidelines for bloodproducts transfusion had not yet been established [3-6]. Then, in 1999, the guidelines for administration of blood preparations were released from the Japanese Ministry of Health and Welfare [7]. Indications of FFP use have been limited to reduce consumption of FFP.

Several studies have suggested the involvement of FFP in pulmonary complications and surgical-site infections (SSI) after surgery $[8,9]$. In recent years, the use of FFP has partially been replaced by albumin preparations. However, there are no standardized guidelines for the use of albumin preparations [10-13]. On the other hand, in perioperative management of hepatectomy for HCC, coagulopathy and albumin composition dysfunction by concomitant chronic liver disease are not unusual, and administration of blood components may be essential. Therefore, the usefulness and risk of blood-products use in perioperative management of hepatectomy for HCC needs to be evaluated. In this study, we retrospectively 
investigated factors pertinent to pulmonary complications and SSI after hepatectomy for HCC to clarify risk factors for such complications, with special reference to perioperative blood-products use.

\section{Methods}

Between January 2000 and December 2006, 101 patients underwent hepatectomy for HCC in the Department of Surgery, Jikei University Hospital. Of these, two patients who required plasma exchange for postoperative liver failure were excluded, and the remaining 99 patients were studied. Generally, the extent of hepatectomy was determined based on $\mathrm{ICG}_{\mathrm{R} 15}$ before surgery and hepatic reserve, as described by Makuuchi et al. [14]. The use of blood products was determined by attending surgeons, and the dose of blood products given was judged based on intraoperative blood loss, and postoperative hemoglobin level, platelet count, serum albumin level, and prothrombin time (PT).

We investigated the association of pulmonary complications and SSI with the following 16 factors: age; gender; preoperative $\mathrm{ICG}_{\mathrm{R} 15}$; type of resection; concomitant resection of other digestive organs; duration of operation; blood loss; hepatitis virus status; postoperative data of minimum platelet count (min Plt), maximum serum total bilirubin (max T-Bil), minimum serum albumin (min Alb), or minimum prothrombin time (min PT); and the dose of red-bloodcell concentration (RC), FFP, platelet concentration (PC), or albumin given. Pulmonary complications were defined as postoperative pneumonia; postoperative respiratory failure with pyrexia, dyspnea, and a pulmonary infiltrate on chest X-rays; or pleural effusion that required thoracentesis. SSI was defined as surgical wound infection with purulent discharge and bacterial isolation, or abdominal abscess with pyrexia. The type of resection was classified into two types:

Table 1 Types of resection

\begin{tabular}{lc}
\hline Type of resection & Number \\
\hline Anatomical hepatic resection & \\
Extended right lobectomy & 3 \\
Extended left lobectomy & 2 \\
Right lobectomy & 12 \\
Left lobectomy & 2 \\
Posterior segmentectomy & 3 \\
Lateral segmentectomy & 5 \\
Subsegmentectomy & 6 \\
Caudate lobectomy & 2 \\
Limited partial resection & 64 \\
\hline
\end{tabular}

anatomical hepatectomy (extended lobectomy, lobectomy, segmentectomy, or subsegmentectomy) and limited partial resection.

Statistical analysis

The data are expressed as mean \pm SD. Univariate analysis was performed using non-paired Student's $t$ test and $\chi^{2}$ test.

Table 2 Postoperative complications after hepatectomy

\begin{tabular}{lc}
\hline Complications & Number \\
\hline SSI & 12 \\
Surgical wound infection & 1 \\
Intraperitoneal abscess & \\
Pulmonary complication & 9 \\
Postoperative pneumonia & 3 \\
Respiratory failure & 1 \\
Pleural effusion & \\
Others & 6 \\
Bile leakage & 1 \\
Hepatic failure & 2 \\
Small-bowel obstraction & 1 \\
Intractable ascites & 1 \\
Upper gastrointestinal hemorrhage & \\
\hline
\end{tabular}

SSI Surgical site infection

Table 3 Patient characteristics

\begin{tabular}{ll}
\hline Variable & Data \\
\hline Age (years) & $61.2 \pm 11.1$ \\
Gender (male:female) & $84: 15$ \\
ICG $_{\mathrm{R} 15}(\%)$ & $14.2 \pm 9.4$ \\
Type of resection (anatomical:partial) & $35: 64$ \\
Resection of digestive organs (yes:no) & $6: 93$ \\
Duration of operation (min) & $287.7 \pm 120.3$ \\
Blood loss (g) & $1,097.4 \pm 1,222.5$ \\
Hepatitis virus (HBV:HCV:no) & $39: 43: 17$ \\
Max T-Bil (mg/dl) & $1.8 \pm 1.0$ \\
Min PT (\%) & $69.7 \pm 12.9$ \\
Min Plt ( $\left.\times 10^{3} / \mu l\right)$ & $115.8 \pm 46.0$ \\
Min Alb (g/dl) & $3.0 \pm 0.4$ \\
RC given (units) & $1.9 \pm 3.9$ \\
FFP given (units) & $8.2 \pm 14.5$ \\
PC given (units) & $1.5 \pm 5.8$ \\
Albumin given (g) & $49.9 \pm 99.3$ \\
\hline
\end{tabular}

$H B V$ Hepatitis B virus, $H C V$ hepatitis $\mathrm{C}$ virus, $\max T$-Bil maximum serum postoperative total bilirubin, $\min P T$ minimum postoperative prothrombin time, min Plt minimum postoperative platelet, $\min \mathrm{Alb}$ minimum postoperative serum albumin, $R C$ red-blood-cell concentration, $F F P$ fresh frozen plasma, $P C$ platelet concentration

Data are mean \pm SD unless otherwise stated 
Table 4 Univariate analysis of clinical variables and SSI after hepatectomy
SSI Surgical site infection, $H B V$ hepatitis $\mathrm{B}$ virus, $H C V$ hepatitis $\mathrm{C}$ virus, $\max \mathrm{T}$-Bil maximum postoperative serum total bilirubin, $\min P T$ minimum postoperative prothrombin time, min Plt minimum postoperative platelet, min Alb minimum postoperative serum albumin, $R C$ red-blood-cell concentration, FFP fresh frozen plasma, $P C$ platelet concentration

Table 5 Univariate analysis of clinical variables and postoperative pulmonary complications after hepatectomy
$H B V$ Hepatitis B virus, $H C V$ hepatitis $\mathrm{C}$ virus, $\max T$-Bil maximum postoperative serum total bilirubin, $\min P T$ minimum postoperative prothrombin time, min Plt minimum postoperative platelet, $\min$ Alb minimum postoperative serum albumin, $R C$ red-blood-cell concentration, $F F P$ fresh frozen plasma, $P C$ platelet concentration

\begin{tabular}{lccc}
\hline Factor & SSI & & $\begin{array}{l}P \text { value } \\
\text { (univariate) }\end{array}$ \\
\cline { 2 - 3 } & Yes $(n=13)$ & No $(n=86)$ & \\
\hline Age (years) & $59.5 \pm 8.0$ & $61.4 \pm 11.4$ & 0.553 \\
Gender (male:female) & $13: 0$ & $71: 15$ & 0.102 \\
ICG $_{\mathrm{R} 15}(\%)$ & $14.3 \pm 6.0$ & $14.1 \pm 9.8$ & 0.971 \\
Type of resection (anatomical:partial) & $5: 8$ & $30: 56$ & 0.801 \\
Resection of digestive organs (yes:no) & $1: 12$ & $5: 81$ & 0.791 \\
Duration of operation (min) & $325.8 \pm 116.0$ & $282.0 \pm 120.6$ & 0.223 \\
Blood loss (g) & $1,188.8 \pm 1,171.9$ & $1,083.6 \pm 1,236.0$ & 0.774 \\
Hepatitis virus (HBV:HCV:no) & $4: 6: 3$ & $35: 37: 14$ & 0.736 \\
Max T-Bil (mg/dl) & $2.2 \pm 1.3$ & $1.7 \pm 1.0$ & 0.109 \\
Min PT (\%) & $69.5 \pm 15.5$ & $69.8 \pm 12.5$ & 0.951 \\
Min Plt ( $\left.\times 10^{3} / \mu \mathrm{l}\right)$ & $110.1 \pm 45.4$ & $116.6 \pm 46.3$ & 0.634 \\
Min Alb (g/dl) & $2.9 \pm 0.4$ & $3.1 \pm 0.4$ & 0.230 \\
RC given (units) & $2.0 \pm 3.8$ & $1.9 \pm 3.9$ & 0.937 \\
FFP given (units) & $15.2 \pm 23.2$ & $7.1 \pm 12.6$ & 0.063 \\
PC given (units) & $1.5 \pm 5.5$ & $1.5 \pm 5.9$ & 0.961 \\
Albumin given (g) & $78.8 \pm 200.2$ & $45.5 \pm 74.5$ & 0.261 \\
\hline
\end{tabular}

\begin{tabular}{lccc}
\hline Factor & \multicolumn{2}{l}{ Pulmonary complications } & $\begin{array}{c}P \text { value } \\
\text { (univariate) }\end{array}$ \\
\cline { 2 - 3 } & Yes $(n=13)$ & No $(n=86)$ & 0.245 \\
\hline Age (years) & $64.5 \pm 8.3$ & $60.6 \pm 11.3$ & 0.012 \\
Gender (male:female) & $8: 5$ & $76: 10$ & 0.874 \\
ICG $_{\mathrm{R} 15}(\%)$ & $13.8 \pm 7.2$ & $14.2 \pm 9.7$ & 0.382 \\
Type of resection (anatomical:partial) & $6: 7$ & $29: 57$ & 0.326 \\
Resection of digestive organs (yes:no) & $0: 13$ & $6: 80$ & 0.164 \\
Duration of operation (min) & $331.2 \pm 132.9$ & $281.2 \pm 117.8$ & 0.082 \\
Blood loss (g) & $1,647.6 \pm 1,858.2$ & $1,014.2 \pm 1,087.3$ & 0.867 \\
Hepatitis virus (HBV:HCV:no) & $6: 5: 2$ & $33: 38: 15$ & 0.043 \\
Max T-Bil (mg/dl) & $2.3 \pm 1.6$ & $1.7 \pm 0.9$ & 0.068 \\
Min PT (\%) & $63.4 \pm 13.5$ & $70.7 \pm 12.6$ & 0.840 \\
Min Plt ( $\left.\times 10^{3} / \mu l\right)$ & $113.3 \pm 71.3$ & $116.1 \pm 41.9$ & 0.682 \\
Min Alb (g/dl) & $3.0 \pm 0.5$ & $3.0 \pm 0.4$ & 0.007 \\
RC given (units) & $4.6 \pm 6.6$ & $1.5 \pm 3.2$ & $<0.001$ \\
FFP given (units) & $26.8 \pm 25.2$ & $5.3 \pm 9.6$ & 0.286 \\
PC given (units) & $3.1 \pm 7.5$ & $1.2 \pm 5.5$ & $<0.001$ \\
Albumin given (g) & $179.8 \pm 211.7$ & $30.2 \pm 45.4$ & \\
\hline
\end{tabular}

Multivariate analysis was performed using logistic-regression analysis. A $P$ value $<0.05$ was regarded as significant.

\section{Results}

Type of resection, postoperative complications, and patient characteristics

Types of resection are listed in Table 1 and postoperative complications in Table 2. Postoperative complications developed in 33 of the 99 patients (33.3\%), including pulmonary complications in 13, SSI in 13, and hospital death due to respiratory failure in 1 patient $(1.1 \%)$. Patient characteristics are listed in Table 3.

Association between clinical variables and postoperative SSI

Table 4 lists the relationship between clinical variables and SSI after hepatectomy for HCC. In univariate analysis, the incidence of SSI did not correlate with any factors. 
Association between clinical variables

and postoperative pulmonary complications

Table 5 lists the relationship between clinical variables and pulmonary complications after hepatectomy for HCC. In univariate analysis, pulmonary complication was more common in females $(P=0.012)$ and associated with higher max T-Bil $(P=0.043)$, and dose of $\mathrm{RC}$ given $(P=0.007)$, FFP given $(P<0.001)$ and albumin given $(P<0.001)$. In multivariate analysis, dose of FFP given $(P=0.031)$ and albumin given $(P=0.020)$ were associated with pulmonary complications (Table 6), which suggests that excessive FFP or albumin use may cause pulmonary complications. Table 7 lists the clinical parameters of 13 patients with postoperative pulmonary complications.

Table 6 Multivariate analysis of clinical variables and postoperative pulmonary complications after hepatectomy

\begin{tabular}{lll}
\hline Factor & Odds ratio $(95 \% \mathrm{CI})$ & $\begin{array}{l}P \text { value } \\
\text { (multivariate) }\end{array}$ \\
\hline Gender (female) & $4.986(0.889-27.956)$ & 0.068 \\
Max T-Bil (mg/dl) & $0.405(0.122-1.345)$ & 0.140 \\
RC given (units) & $0.968(0.760-1.232)$ & 0.791 \\
FFP given (units) & $1.089(1.008-1.177)$ & 0.031 \\
Albumin given $(\mathrm{g})$ & $1.015(1.002-1.027)$ & 0.020
\end{tabular}

Max T-Bil Maximum postoperative serum total bilirubin, FFP fresh frozen plasma

\section{Discussion}

In 1985, the Hospital Transfusion Committee in the United States recommended criteria for blood-products administration [15]. In Europe and in the United States, bloodproducts administration has been minimized for many years [16-19]. In Japan, on the other hand, the use of FFP transfusion has been rather liberal to maintain the circulating plasma volume and supplement the coagulation factors. In Japan, the guidelines for administration of blood preparations were established by the Ministry of Health and Welfare in 1999 [7]. FFP transfusion is limited to supplementing coagulation factors, while albumin preparation is recommended to supplement plasma protein. This practice did reduce the usage of FFP. Japanese guidelines for administration of blood preparations advocate that FFP should be indicated for patients with a PT value of $30 \%$ or less and an activated partial thromboplastin time value 1.5 times higher than the reference value established at each hospital. In addition, FFP should be indicated when the volume of blood loss during surgery corresponds to $100 \%$ or more of the circulating blood volume. To maintain the circulating plasma volume, isotonic albumin preparations should be administered. For protein source supplementation, intravenous hyperalimentation or enteral nutrition is indicated. Various plasma fraction preparations have been developed and administered, which contribute to sparing the use of FFP.

Excessive intraoperative blood loss and blood transfusion affect postoperative complications and prognoses [2, $20,21]$, and recent studies have reported a relationship

Table 7 Clinical variables of patients with postoperative pulmonary complications

\begin{tabular}{|c|c|c|c|c|c|c|c|c|c|c|c|c|c|c|c|}
\hline $\begin{array}{l}\text { Age } \\
\text { (years) }\end{array}$ & Gender & $\begin{array}{l}\mathrm{ICG}_{\mathrm{R} 15} \\
(\%)\end{array}$ & $\begin{array}{l}\text { Type of } \\
\text { resection }\end{array}$ & $\begin{array}{l}\text { Resection of } \\
\text { digestive } \\
\text { organs }\end{array}$ & $\begin{array}{l}\text { Duration of } \\
\text { operation } \\
(\min )\end{array}$ & $\begin{array}{l}\text { Blood } \\
\text { loss } \\
(\mathrm{g})\end{array}$ & $\begin{array}{l}\text { Hepatitis } \\
\text { virus }\end{array}$ & $\begin{array}{l}\text { Max } \\
\text { T-Bil } \\
(\mathrm{mg} / \mathrm{dl})\end{array}$ & $\begin{array}{l}\text { Min } \\
\text { PT } \\
(\%)\end{array}$ & $\begin{array}{l}\text { Min Plt } \\
\left(\times 10^{3} /\right. \\
\mu \mathrm{l})\end{array}$ & $\begin{array}{l}\text { Min } \\
\text { Alb } \\
(\mathrm{g} / \mathrm{dl})\end{array}$ & $\begin{array}{l}\mathrm{RC} \\
\text { given } \\
\text { (units) }\end{array}$ & $\begin{array}{l}\text { FFP } \\
\text { given } \\
\text { (units) }\end{array}$ & $\begin{array}{l}\mathrm{PC} \\
\text { given } \\
\text { (units) }\end{array}$ & $\begin{array}{l}\text { Albumin } \\
\text { given }(\mathrm{g})\end{array}$ \\
\hline 64 & M & 16 & Anatomical & No & 290 & 1,104 & $\mathrm{HCV}$ & 2.1 & 58 & 42 & 2.7 & 0 & 40 & 20 & 12.5 \\
\hline 57 & M & 8 & Anatomical & No & 400 & 2,650 & HBV & 1.1 & 63 & 292 & 3.2 & 4 & 21 & 0 & 62.5 \\
\hline 57 & M & 13 & Partial & No & 195 & 225 & HBV & 1.1 & 82 & 122 & 3.4 & 0 & 0 & 0 & 0 \\
\hline 74 & $\mathrm{~F}$ & 18 & Anatomical & No & 330 & 4,500 & $\mathrm{HCV}$ & 6.6 & 58 & 85 & 3.4 & 20 & 64 & 0 & 212.5 \\
\hline 67 & $\mathrm{~F}$ & 34 & Partial & No & 135 & 475 & $\mathrm{HCV}$ & 2.8 & 37 & 70 & 2.5 & 4 & 48 & 0 & 275 \\
\hline 66 & M & 8 & Anatomical & No & 330 & 610 & No & 3.2 & 66 & 122 & 2.5 & 4 & 24 & 0 & 362.5 \\
\hline 76 & $\mathrm{M}$ & 15 & Anatomical & No & 300 & 1,300 & $\mathrm{HBV}$ & 2.3 & 64 & 113 & 3.0 & 2 & 12 & 0 & 50 \\
\hline 76 & $\mathrm{~F}$ & 7 & Partial & No & 490 & 4,235 & No & 2.5 & 57 & 92 & 3.4 & 12 & 24 & 20 & 200 \\
\hline 71 & M & 12 & Anatomical & No & 585 & 5,230 & $\mathrm{HCV}$ & 2.1 & 72 & 54 & 4.1 & 14 & 40 & 0 & 325 \\
\hline 66 & $\mathrm{~F}$ & 15 & Partial & No & 410 & 250 & $\mathrm{HCV}$ & 1.3 & 66 & 73 & 2.6 & 0 & 0 & 0 & 100 \\
\hline 58 & M & 16 & Partial & No & 210 & 10 & $\mathrm{HBV}$ & 0.9 & 87 & 210 & 3.2 & 0 & 0 & 0 & 0 \\
\hline 53 & $\mathrm{M}$ & 10 & Partial & No & 450 & 730 & HBV & 3.5 & 49 & 80 & 2.8 & 0 & 75 & 0 & 737.5 \\
\hline 53 & $\mathrm{~F}$ & 7 & Partial & No & 180 & 100 & HBV & 1 & 66 & 117 & 2.6 & 0 & 0 & 0 & 0 \\
\hline
\end{tabular}

$H B V$ Hepatitis B virus, $H C V$ hepatitis $\mathrm{C}$ virus, $\max T$ - $B i l$ maximum postoperative serum total bilirubin, $\min P T$ minimum postoperative prothrombin time, min $P l t$ minimum postoperative platelet, $\min A l b$ minimum postoperative serum albumin, $R C$ red-blood-cell concentration, $F F P$ fresh frozen plasma, $P C$ platelet concentration 
between allogenic blood transfusion and immunomodulatory effects [22-26]. Concerning the mechanism for immunosuppressive effects of blood transfusion, soluble HLA class I molecules and soluble Fas-ligands released by leukocytes in blood-transfusion preparations inhibit the activity of NK cells and cytotoxic T cells, which reduce immune capacity, inducing postoperative infectious diseases such as postoperative pneumonia and wound infection [8, 26-31]. Since blood preparations are derived from donations, massive administration of blood preparations should be avoided.

Nevertheless, in perioperative management of hepatectomy for HCC, it is sometimes necessary to supplement blood components following extensive blood loss and hepatic dysfunction. Administration of blood products including FFP and albumin preparation at an optimal dose may be important to prevent postoperative complications. Changes in the condition during or after hepatectomy differ among patients with hepatopathy such as liver cirrhosis; such patients often require blood products including FFP and albumin preparation therapy. Criteria should be established for the use of blood products in hepatic surgery for cirrhotic patients and in perioperative management, so that complications of hepatic resection can be minimized. Based on these guidelines, conditions requiring transfusion during hepatectomy or in perioperative management and side effects of blood products use should be reviewed, and criteria for administering blood products must be established.

\section{References}

1. Makuuchi M, Kosuge T, Takayama T, Yamazaki S, Kakazu T, Miyagawa S, et al. Surgery for small liver cancers. Semin Surg Oncol. 1993;9:294-304.

2. Yamamoto J, Kosuge T, Takayama T, Shimada K, Yamasaki S, Ozaki $\mathrm{H}$, et al. Perioperative blood transfusion promotes recurrence of hepatocellular carcinoma after hepatectomy. Surgery. 1994;115:303-9.

3. Cunningham JD, Fong Y, Shriver C, Melendez JA, Marx WL, Blumgart LH. One hundred consecutive hepatic resections, blood loss, transfusion, and operative technique. Arch Surg. 1994;129: $1050-6$.

4. Melendez JA, Arslan V, Fischer ME, Wuest D, Jarnagin WR, Fong Y, et al. Perioperative outcomes of major hepatic resections under low central venous pressure anesthesia: blood loss, blood transfusion, and risk of postoperative renal dysfunction. J Am Coll Surg. 1998;187:620-5.

5. Torzilli G, Makuuchi M, Inoue K, Takayama T, Sakamoto Y, Sugawara Y, et al. No-mortality liver resection for hepatocellular carcinoma in cirrhotic and noncirrhotic patients: is there a way? A prospective analysis of our approach. Arch Surg. 1999;134: 984-92.

6. Martin R, Jarnagin WR, Fong Y, Biernacki P, Blumgart LH, DeMatteo RP. The use of fresh frozen plasma after major hepatic resection for colorectal metastasis: is there a standard for transfusion? J Am Coll Surg. 2003;196:402-9.

7. Bureau of Medicinal Safety, Ministry of Health and Welfare. Guidelines for administering blood preparations. Medical and Pharmaceutical Notification No. 715, 10 June 1999.

8. Vamvakas EC, Carven JH. Exposure to allogeneic plasma and risk of postoperative pneumonia and/or infection in coronary artery bypass graft surgery. Transfusion. 2002;42:107-13.

9. Gajic O, Rana R, Mendez JL, Rickman OB, Lymp JF, Hubmayr $\mathrm{RD}$, et al. Acute lung injury after blood transfusion in mechanically ventilated patients. Transfusion. 2004;44:1468-74.

10. Cochrane Injuries Group. Human albumin administration in critically ill patients: systematic review of randomised controlled trials. Cochrane Injuries Group Albumin Reviewers. BMJ. 1998;317:235-40.

11. Wilkes MM, Navickis RJ. Patient survival after human albumin administration: a meta-analysis of randomized, controlled trials. Ann Intern Med. 2001;135:149-64.

12. Finfer S, Bellomo R, Boyce N, French J, Myburgh J, Norton R. SAFE study investigators. A comparison of albumin and saline for fluid resuscitation in the intensive care unit. N Engl J Med. 2004;350:2247-56.

13. Vincent JL, Sakr Y, Reinhart K, Sprung CL, Gerlach H, Ranieri VM. Sepsis occurrence in acutely ill patients' investigators. Is albumin administration in the acutely ill associated with increased mortality? Results of the SOAP study. Crit Care. 2005;9:R745-54.

14. Miyagawa S, Makuuchi M, Kawasaki S, Kakazu T. Criteria for safe hepatic resection. Am J Surg. 1995;169:589-94.

15. Grindon AJ, Tomasulo PS, Bergin JJ, Klein HG, Miller JD, Mintz PD. The hospital transfusion committee: guidelines for improving practice. JAMA. 1985;253:540-3.

16. Contreras M, Ala FA, Greaves M, Jones J, Levin M, Machin SJ, et al. Guidelines for use of fresh frozen plasma. British Committee for Standards in Haematology, Working Party of the Blood Transfusion Task Force. Transfus Med. 1992;2:57-63.

17. Barnette RE, Fish DJ, Eisenstaedt RS. Modification of freshfrozen plasma transfusion practices through educational intervention. Transfusion. 1990;30:253-7.

18. Shanberge JN, Quattrociocchi-Longe T. Analysis of fresh frozen plasma administration with suggestions for ways to reduce usage. Transfus Med. 1992;2:189-94.

19. Stehling L, Luban NL, Anderson KC, Sayers MH, Long A, Attar $S$, et al. Guidelines for blood utilization review. Transfusion. 1994;34:438-48.

20. Yanaga K, Kanematsu T, Takenaka K, Matsumata T, Yoshida Y, Sugimachi K. Hepatic resection for hepatocellular carcinoma in elderly patients. Am J Surg. 1988;155:238-41.

21. Nagao T, Inoue S, Goto S, Mizuta T, Omori Y, Kawano N, et al. Hepatic resection for hepatocellular carcinoma. Clinical features and long-term prognosis. Ann Surg. 1987;205:22-40.

22. Brunson ME, Alexander JW. Mechanisms of transfusion-induced immunosuppression. Transfusion. 1990;30:651-8.

23. Blajchman MA, Bordin JO. Mechanisms of transfusion-associated immunosuppression. Curr Opin Hematol. 1994;1:457-61.

24. Blajchman MA. Immunomodulatory effects of allogeneic blood transfusions: clinical manifestations and mechanisms. Vox Sang. 1998;74(Suppl 2):315-9.

25. Magee CC, Sayegh MH. Peptide-mediated immunosuppression. Curr Opin Immunol. 1997;9:669-75.

26. Krensky AM, Clayberger C. Structure of HLA molecules and immunosuppressive effects of HLA derived peptides. Int Rev Immunol. 1996;13:173-85.

27. Ashkenazi A, Dixit VM. Death receptors: signaling and modulation. Science. 1998;281:1305-8. 
28. Pitti RM, Marsters SA, Lawrence DA, Roy M, Kischkel FC, Dowd P, et al. Genomic amplification of a decoy receptor for Fas ligand in lung and colon cancer. Nature. 1998;396:699-703.

29. Ghio M, Contini P, Mazzei C, Brenci S, Barberis G, Filaci G, et al. Soluble HLA class I, HLA class II and Fas ligand in blood components: a possible key to explain the immnomodulatory effects of allogeneic blood transfusions. Blood. 1999;93:1770-7.
30. Puppo F, Contini P, Ghio M, Brenci S, Scudeletti M, Filaci G, et al. Soluble human MHC class I molecules induce soluble Fas ligand secretion and trigger apoptosis in activated CD8(+) Fas (CD95)(+) T lymphocytes. Int Immunol. 2000;12:195-203.

31. Puppo F, Ghio M, Contini P, Mazzei C, Indiveri F. Fas, Fas ligand, and transfusion immunomodulation. Transfusion. 2001; 41:416-8. 